\title{
SOEP
}

SOEPpapers

on Multidisciplinary Panel Data Research

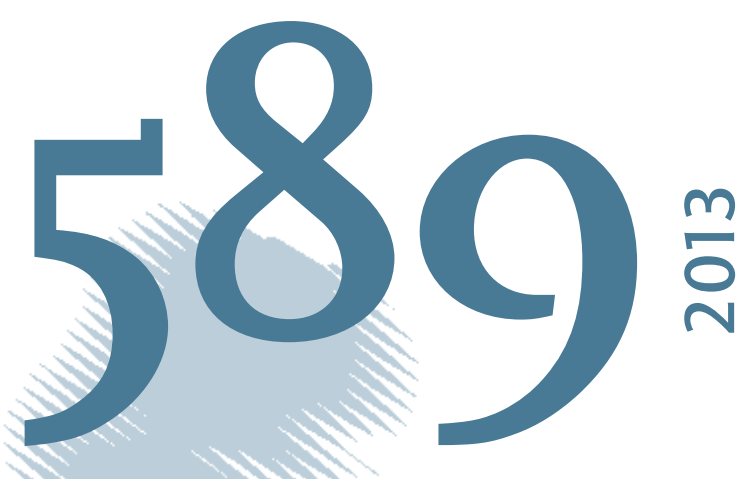

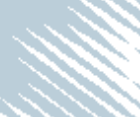
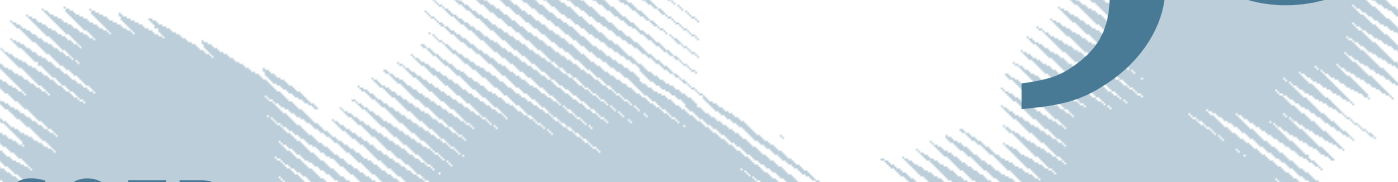

$\stackrel{m}{\circ}$

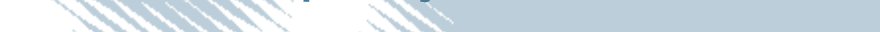

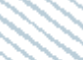
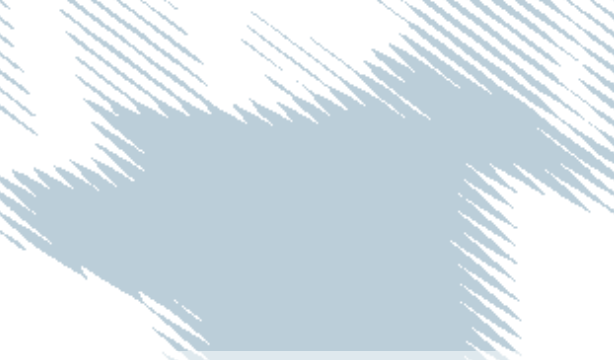

\section{Locus of Control and Low-Wage Mobility}

Daniel D. Schnitzlein and Jens Stephani 


\section{SOEPpapers on Multidisciplinary Panel Data Research}

at DIW Berlin

This series presents research findings based either directly on data from the German SocioEconomic Panel Study (SOEP) or using SOEP data as part of an internationally comparable data set (e.g. CNEF, ECHP, LIS, LWS, CHER/PACO). SOEP is a truly multidisciplinary household panel study covering a wide range of social and behavioral sciences: economics, sociology, psychology, survey methodology, econometrics and applied statistics, educational science, political science, public health, behavioral genetics, demography, geography, and sport science.

The decision to publish a submission in SOEPpapers is made by a board of editors chosen by the DIW Berlin to represent the wide range of disciplines covered by SOEP. There is no external referee process and papers are either accepted or rejected without revision. Papers appear in this series as works in progress and may also appear elsewhere. They often represent preliminary studies and are circulated to encourage discussion. Citation of such a paper should account for its provisional character. A revised version may be requested from the author directly.

Any opinions expressed in this series are those of the author(s) and not those of DIW Berlin. Research disseminated by DIW Berlin may include views on public policy issues, but the institute itself takes no institutional policy positions.

The SOEPpapers are available at

http://www.diw.de/soeppapers

\section{Editors:}

Jürgen Schupp (Sociology)

Gert G. Wagner (Social Sciences, Vice Dean DIW Graduate Center)

Conchita D'Ambrosio (Public Economics)

Denis Gerstorf (Psychology, DIW Research Director)

Elke Holst (Gender Studies, DIW Research Director)

Frauke Kreuter (Survey Methodology, DIW Research Professor)

Martin Kroh (Political Science and Survey Methodology)

Frieder R. Lang (Psychology, DIW Research Professor)

Henning Lohmann (Sociology, DIW Research Professor)

Jörg-Peter Schräpler (Survey Methodology, DIW Research Professor)

Thomas Siedler (Empirical Economics)

C. Katharina Spieß (Empirical Economics and Educational Science)

ISSN: 1864-6689 (online)

German Socio-Economic Panel Study (SOEP)

DIW Berlin

Mohrenstrasse 58

10117 Berlin, Germany

Contact: Uta Rahmann | soeppapers@diw.de 


\title{
Locus of Control and Low-Wage Mobility
}

\author{
Daniel D. Schnitzlein \\ DIW Berlin, University Hamburg
}

Jens Stephani

IAB Nuremberg

\begin{abstract}
We investigate whether non-cognitive skills - in particular Locus of Control - are important determinants of the labour market processes at the low-wage margin. Based on data from the German Socio-Economic Panel, we estimate dynamic multinomial logit models with random effects and investigate whether Locus of Control influences the probability of being higherpaid or low-paid as well as the probability of escaping low wages by moving up to higherpaid employment. Our results reveal a significant amount of state dependence in low pay even after controlling for Locus of Control and other non-cognitive skills. Furthermore, compared to individuals with an external Locus of Control, individuals with a more internal Locus of Control have a significantly higher probability of being higher-paid instead of low-paid. Conditional on being low-paid, individuals with an internal Locus of Control additionally have a significantly higher probability of moving to higher-paid employment in the following year than individuals with an external Locus of Control.
\end{abstract}

JEL-Codes： J30, J60

Keywords: low-wage, wage mobility, personality, non-cognitive skills, inequality, SOEP

\section{Acknowledgements}

We thank Claus Schnabel, Jürgen Schupp, and Alexander Mosthaf for valuable comments and suggestions.

Correspondence to: Jens Stephani; IAB Nuremberg; Regensburger Strasse 104; 90478

Nuremberg; Germany; tel.: +49-(0)911-179-6315; e-mail: jens.stephani@iab.de 


\section{Introduction}

In this paper, we analyse whether personality traits or, more generally, non-cognitive skills are important determinants of the labour market processes at the low-wage margin, which is a question that has not been investigated previously. Our main focus is an individual's perceived Locus of Control - the extent to which an individual believes that he or she has control over his or her life. In addition, our data allow us to control for the Big Five personality traits and measures of reciprocity.

Over the last two decades, the literature has developed on the importance of non-cognitive skills for economic and social outcomes (see Almlund et al., 2011 for an extensive overview). Heckman et al. (2006) show that for many labour market outcomes, non-cognitive skills have the same predictive power as cognitive skills, which are the classic focus in economic analyses. Non-cognitive skills help to explain the observed variance in earnings (see Heckman et al., 2006, Müller and Plug, 2006 and Groves, 2005 for evidence from the US; Heineck and Anger, 2010 for evidence from Germany; Heineck, 2011 and Groves, 2005 for evidence from the UK), educational outcomes (Barón and Cobb-Clark, 2010) and occupational choices (Antecol and Cobb-Clark, forthcoming). Blázquez Cuesta and Budría (2012) show that non-cognitive skills affect unemployment persistence, and Caliendo et al. (2010) find that non-cognitive skills influence job search behaviour.

However, the impact of Locus of Control and other non-cognitive skills on the wage mobility of low-wage workers has not been investigated to date. Previous studies on low-wage mobility have shown that the chances of escaping the low-wage sector are higher for males than females, for younger individuals than for older individuals and for more highly skilled individuals than less skilled individuals. The odds of leaving the low-wage sector are also higher for workers in certain industries, in large firms versus small firms and in firms with a low percentage of women or low-wage workers. In addition, there is evidence for the existence of state dependence in low pay, i.e., being low-paid today increases the probability of being low-paid in the future. In addition, the results of previous studies imply that the factors mentioned above account only for a part of the heterogeneity which is relevant for the upward wage mobility of low-wage workers. ${ }^{1}$ A significant part of this heterogeneity remains

\footnotetext{
${ }^{1}$ For example, Asplund et al. (1998), the European Commission (2004) and Clark and Kanellopoulos (2013) provide cross-country evidence for Europe. There are also a number of country-specific analyses, such as the studies by Andersson et al. (2005) for the US; Stewart and Swaffield (1999), Stewart (2007) and Cappellari and Jenkins (2008a) for the UK; Blázquez Cuesta (2008) for Spain; and Cappellari (2002; 2007) for Italy. For Germany, see, e.g., Uhlendorff (2006); Schank et al. (2009); Mosthaf et al. (2011); Aretz and Gürtzgen (2012); Knabe and Plum (2013); Mosthaf (forthcoming); and Stephani (2012; 2013).
} 
unobserved. A part of this unobserved heterogeneity could be due to differing levels of noncognitive skills between individual workers.

If Locus of Control is a relevant determinant for escaping low-wage employment, there are two important implications for social policy. (i) First, potential programs to support low-wage workers have to consider the existing heterogeneity in non-cognitive skills between different individuals. For example, the individuals who believe that they do not have much influence on their future will need more support by case workers than individuals who believe that they have full control over their life. (ii) Second, while Locus of Control and other non-cognitive skills are seen as rather stable in adulthood (Cobb-Clark and Schurer, 2012, 2013) $)^{2}$, they are malleable in early childhood and adolescence and therefore can be targeted by interventions. ${ }^{3}$ If having a more internal individual level of Locus of Control significantly increases the individual chances of low-wage workers escaping low pay, internalising an individuals' Locus of Control may be a good starting point for policy interventions during childhood. ${ }^{4}$

In this paper, we investigate the impact of Locus of Control on the wage mobility of low-wage workers using dynamic multinomial logit models with random effects that consider initial conditions and state dependence. In addition, we control for possible correlations with other non-cognitive skills, such as the Big Five personality traits and reciprocity. We contribute to the literature by answering the following research questions: does Locus of Control influence the probability of being low-paid or higher-paid? Does the extent of state dependence in low pay vary with Locus of Control, i.e., does a specific individual level of Locus of Control facilitate escaping low pay? The paper is structured as follows. Section 2 presents theoretical considerations and derives our hypotheses on the influence of Locus of Control on transitions into and out of the low-wage sector. Section 3 describes our data. Section 4 outlines our

\footnotetext{
${ }^{2}$ The stability of non-cognitive skills in adulthood is a debated topic in the psychological literature. Psychologists are mainly interested in the mean-level stability and rank-order stability of personality traits. While the traditional view is that personality is stable at least after age 30 (e.g. Costa and McCrae, 1988), Roberts and DelVecchio (2000) and Roberts et al. (2006) challenge this view and present an extensive meta-analysis of rank-order and mean-level change in personality traits. For both concepts, they find that values change over the full age range of individuals. Specht et al. (2013) find similar results using German SOEP data. However, Cobb-Clark and Schurer (2013) point out that in an economic context intra-individual stability is the more relevant measure. By analysing the effects of life events on individuals' non-cognitive skills, they find high intra-individual stability for the Big Five (Cobb-Clark and Schurer, 2012) and Locus of Control (Cobb-Clark and Schurer, 2013) using Australian data for individuals of working ages. Specht et al. (2011) find high intra-individual stability of these non-cognitive skills based on German SOEP data for working aged individuals.

${ }^{3}$ See, for example, Heckman et al. (2012) for an overview on the mechanisms through which one specific early intervention programme, namely the Perry Pre-School programme, supported the participants.

${ }^{4}$ A fruitful target is to support the children of disadvantaged families. Stephens and Delys (1973) argue that children of disadvantaged families are less convinced they have control over their lives already at an early age relative to other children. Peter (2013) shows that a mother's job loss has a causal, negative effect on children's non-cognitive skills.
} 
empirical approach. Section 5 presents and discusses the results, and section 6 concludes the paper.

\section{Measures of non-cognitive skills}

\subsection{Locus of Control}

The psychological concept of perceived Locus of Control (LoC) dates back to Rotter (1966). LoC measures the extent to which an individual believes that he or she controls the events in his or her life. Psychologists differentiate between individuals with a more internal LoC and individuals with a more external LoC. Individuals with a more internal LoC are convinced that the events that happen in their life are caused by their actions and their behaviour. Individuals with a more external LoC have a more fatalistic view on their life. They believe that their influence on their life is very limited and that what happens to them is caused not by their decisions but is mainly the result of faith or luck. ${ }^{5}$

This sense of control over one's life has important implications for an individual's human capital investments. Being convinced that effort will lead to success leads to comparatively higher expected returns on their human capital investments because the expected probability to fail is lower. Therefore, these internal LoC individuals invest more in their human capital than their external LoC counterparts (Caliendo et al., 2010). Barón and Cobb-Clark (2010) showed that a more internal LoC is associated with positive educational outcomes. ${ }^{6}$ But LoC also influences labour market behaviour other than investments in education. Caliendo et al. (2010) analyse the role of LoC for the job search behaviour of unemployed persons. They find that having a more internal LoC is associated with higher search intensity, a higher job offer rate and a higher reservation wage than having an external LoC. In addition, Caliendo et al. note that it is plausible that an internal LoC is related to positive labour market outcomes and economic success in general.

In the context of our study, we therefore expect that:

H1: Individuals with a more internal LoC are more likely to work in higher-wage employment than individuals with a more external LoC.

\footnotetext{
${ }^{5}$ The data on non-cognitive skills used in this study are also used for research by psychologists. See, for example, Dyrenforth et al. (2010) for the relationship between personality and satisfaction, Lucas and Donnellan (2011) and Specht et al. (2011) for the development of personality, and Specht et al. (2013) for the development of LoC over the life course.

${ }^{6}$ See Wang et al. (1999) for a detailed overview of the sociological and psychological literature on the relationship between LoC and educational outcomes.
} 
$\mathrm{H} 2$ : Conditional on being employed in the low-wage sector, the individual probability to move to higher-wage employment is positively correlated with a more internal LoC.

Although the focus of this paper is on Locus of Control, we also include other non-cognitive skills to control for possible correlations between these non-cognitive skills and Locus of Control (Almlund et al., 2011). More specifically, we follow the literature and control for the correlation between Locus of Control and the Big Five and reciprocity.

\subsection{Big Five and reciprocity}

The Big Five taxonomy of personality traits (McCrae and Costa Jr., 1999) classifies an individual's personality into 30 personality traits that are grouped into five main factors. These factors are Openness to experience, Conscientiousness, Extraversion, Agreeableness and Neuroticism. Openness to experience is the extent to which individuals are open to new occurrences in their life. Conscientiousness contains the subscales order, competence, dutifulness, achievement striving, self-discipline and deliberation. Individuals with higher scores on Conscientiousness are seen as more effectively organised than those with lower values. Extraversion covers the dimensions of social behaviour towards other people and is the opposite of introversion. Agreeableness also contains dimensions of social behaviour. Individuals with low scores on Agreeableness describe themselves as egocentric and uncooperative. Neuroticism is the opposite of emotional stability.

The third measure of non-cognitive skills considered in this paper is reciprocity. ${ }^{7}$ Reciprocity measures the extent to which an individual is willing to respond to positive or negative behaviour. One can distinguish positive reciprocity, i.e., the extent to which individuals respond positively to positive actions, and negative reciprocity, i.e., the extent to which individuals respond negatively to negative behaviour.

\footnotetext{
${ }^{7}$ Similar to risk and trust measures, reciprocity is usually seen as being a preference and not a personality trait. Preferences may be complementary to personality traits in explaining labour market outcomes (see Becker et al. 2012 for a discussion). Although the focus of this study is on personality traits and not on preferences, we included reciprocity to make our analysis comparable to previous studies on non-cognitive skills (most of which include Locus of Control, the Big Five and reciprocity together). However, our results are robust to the exclusion of reciprocity from our models. For the sake of readability, in this paper, we group Locus of Control, the Big Five and reciprocity into the term "non-cognitive skills".
} 


\section{Data and descriptive evidence}

\subsection{Data}

Our estimates are based on data from the German Socio-Economic Panel Study (SOEP), which is a representative household panel survey that started in 1984 (Wagner et al., 2007). The SOEP conducts annual personal interviews with all household members aged 18 years and older and provides rich information on the socio-demographic characteristics, the family background, and the childhood environment of approximately 20,000 individuals in more than 11,000 families in the most recent wave. The SOEP included measures of LoC, Big Five, and reciprocity in 2005 and repeated measures of the Big Five in 2009 and reciprocity and LoC in 2010 (Richter et al., 2013). All non-cognitive skill measures were included in the main questionnaire and therefore represent self-ratings by the respondents. LoC is measured by seven items, the Big Five are measured by 15 items and reciprocity is measured by six items. The detailed questions are shown in Tables A1, A2 and A3 in the appendix. Each item can be answered on 7-point Likert type scales.

Our analysis is based on data for the years $2006-2011 .^{8}$ We restrict our analysis to West German men who are aged 25-59 in the respective years. Because of the heterogeneous employment trajectories of women, which may additionally interact with their non-cognitive skills, we limit our analysis to men. ${ }^{9}$ Individuals are excluded from our analysis after not participating in the SOEP for at least one year. Because we focus on the core groups of the labour market, we also exclude individuals who are still in the education system, self-employed individuals and early retirees. We use the commonly accepted low-wage threshold of twothirds of the median hourly wage and we calculate this threshold from our sample for each year. ${ }^{10}$ We define three different employment states: i) Higher-wage employment is defined as having a job that pays wages above the low-wage threshold in that year; ii) low-wage employment is defined as having a job that pays wages below the low-wage threshold; and iii) not being working is defined as being unemployed or out of the labour force.

As measures of non-cognitive skills, we use the 2005 data on the psychological constructs discussed above. We do not include the 2009 and 2010 measures for two reasons. First, recent

\footnotetext{
${ }^{8}$ We use SOEPv28.

${ }^{9}$ While it would be interesting to analyse East German men as well, due to data limitations, we are unable to do so. Because the East and West German labour market developed differently with respect to patterns of wage mobility (Riphahn and Schnitzlein, 2011), it is necessary to analyse West German men and East German men separately to obtain meaningful results. However, the small size of the East German SOEP sample would lead to very small cells, some with fewer than 20 observations. Such small cell sizes would not be a reasonable basis for analysis.

${ }^{10}$ We exclude all observations with an hourly real wage lower than $2.5 €$ (in 2010 prices).
} 
empirical contributions show that non-cognitive skills, at least for the age range of our sample, are reasonably stable (Cobb-Clark and Schurer, 2012, 2013). Given these results and the short time range, six years, between the measurement and latest observation year, the 2005 values are reasonable proxies, even for personality, in 2011. The more important reason is that by using the 2005 measures we avoid a reverse causality problem. Although non-cognitive skills are reasonably stable for the age range of our sample ${ }^{11}$, if we used the 2009/2010 measures we would not be able to completely rule out the possibility that these measures are influenced by the transitions that we want to model. ${ }^{12}$

The main descriptive statistics of our sample are shown in Table 1. Our sample consists of 10,456 person-year observations. Approximately $86 \%$ of these observations are higher-wage person-year observations. Approximately 5\% are low-wage observations, and $9 \%$ of the observed person-years are from individuals who were not working. This high proportion of non-working individuals underlines the need to explicitly model this state. Our main variable of interest, LoC, is given both as a continuous variable ranging from 1 (external) to 7 (internal) and as a categorical variable with three levels. The first category of the LoC is a dummy variable that indicates that an individual has a score of LoC of up to four (i.e., an external LoC). The second dummy variable indicates that an individual has a LoC score that is larger than four but less than five (i.e., a medium LoC). The third dummy variable indicates that an individual has a score of LoC larger than five and up to seven (i.e., an internal LoC).

(Table 1 around here)

The average individual score of LoC in the sample is 4.88 for higher-wage workers and 4.50 for low-wage workers. The three dummy variables for LoC show that while $45 \%$ of the higherwage workers report an internal LoC, only $18 \%$ of them report an external LoC. In contrast, low-wage workers are distributed evenly over the three categories of Locus of Control: while $33 \%$ of them report an internal Locus of Control, $34 \%$ of them report an external Locus of Control. Our additional individual control variables show the patterns expected from the existing literature. The next section provides descriptive evidence on our hypotheses.

\footnotetext{
${ }^{11}$ In our sample, $77 \%$ of the respondents answered the questions on Locus of Control both in 2005 and in 2010. The mean change (on a scale from 1-7) between the two years is very small $(-0.03)$. The $25^{\text {th }}$ percentile of the distribution of changes is -0.57 , and the $75^{\text {th }}$ percentile is $0.57 .83 \%$ of the respondents answered the questions concerning the Big Five both in 2005 and in 2009. Again, the mean changes are very small, ranging from -0.1 (Extraversion) to -0.17 (Openness). $78 \%$ of the respondents answered the questions on reciprocity in 2005 and 2010 and report mean changes of -0.05 (positive reciprocity) and -0.02 (negative reciprocity).

${ }^{12}$ See Cobb-Clark and Schurer (2013) for a detailed discussion of potential biases. We follow their suggestions and restrict our sample to the working age population. In addition, according to their suggestions, we reran our models with an age standardised version of our non-cognitive skill measures. The results were not substantively different.
} 


\subsection{Descriptive evidence}

Figure 1 presents descriptive evidence of $\mathrm{H} 1$ by depicting the percentage of individuals in each of the three employment states, higher-wage employment, low-wage employment and not working, by the categories of LoC. The first implication of H1 is that the proportion of higherwage workers should be higher among the group of individuals with a more internal LoC. This implication is clearly supported by Figure 1 because the percentage of workers in higher-wage employment is higher for the internal LoC group. In addition, Figure 1 shows that the percentage of individuals in low-wage employment is decreasing with a more internal LoC. Figure 2 contains evidence on $\mathrm{H} 2$ by depicting the mobility from low-wage employment to higher-wage employment for each group of LoC. The percentage of workers who remain in low-wage employment from one year to the next is decreasing with a more internal LoC, while the percentage of workers who are moving from low pay to higher pay is increasing.

(Figure 1 and Figure 2 around here)

\section{The Econometric Model}

To investigate the impact of Locus of Control on transitions between low pay, higher pay and not working, we use dynamic multinomial logit models with random effects that take into account unobserved heterogeneity, initial conditions and state dependence. ${ }^{13}$ This type of model has been used by others, including Mosthaf et al. (2009) and Mosthaf (forthcoming). We follow these two papers and model the latent probability $Y^{*}$ of an individual $i$ to be in the employment state $j$ (higher-wage employment, low-wage employment, not working) in the year $t=1 \ldots T$ as:

$Y_{i j t}^{*}=X_{i t} \beta_{j}+Y_{i t-1} \alpha_{j}+N C_{i} \gamma_{j}+v_{i j}+\varepsilon_{i j t}$,

where $i=1, \ldots, N ; j=1,2,3$; and $t=2007-2011 . X_{i t}$ is a vector of time-constant and time-varying individual characteristics that are supposed to influence an individual's probability to be in a given employment state. ${ }^{14}$ Following human capital theory and job search

\footnotetext{
${ }^{13}$ Although the focus of this paper is on transitions from low pay to higher pay, we include individuals who are not working in order to take into account the possibly endogenous selection of individuals into this employment state.

${ }^{14}$ Because previous studies have found that establishment characteristics, such as establishment size, impact the wage mobility of low-wage workers, it would be interesting to see whether our results are robust to the inclusion of establishment characteristics. Because there are no establishment characteristics for individuals who are not working, we test the robustness of our models by defining two different sets of explanatory variables for lowwage workers and for individuals who are not working. For the low-wage workers, we include three establishment size dummies; for non-working individuals we do not. Unfortunately, due to the heavy computation involved in estimating dynamic multinomial logit models with random effects that incorporate different sets of explanatory variables, these models do not converge.
} 
theory as well as previous studies on state dependence in low pay ${ }^{15}$, we include in $X_{i t}$ a dummy variable that indicates migration background, age in the linear and in squared form, three dummy variables describing the individual level of education, a dummy variable indicating whether an individual was married in time period $t$ and a variable indicating the number of doctor visits in the last year. The number of doctor visits in the last year is a more objective measure of an individual's health status than self-reported health conditions. $Y_{i t-1}$ is a vector of three dummy variables that describe the lagged employment state in the period $t-1$; this vector captures state dependence. $N C_{i}$ includes the non-cognitive skill Locus of Control measured by the three dummy variables discussed earlier. ${ }^{16}$ We later augment our model by including the Big Five non-cognitive skills: Openness to experience, Conscientiousness, Extraversion, Agreeableness, Neuroticism as well as positive reciprocity and negative reciprocity. $v_{i j}$ is a time-invariant, person-specific random component. $\varepsilon_{i j t}$ is an individualspecific error term that is assumed to be uncorrelated across individuals and time and uncorrelated with $v_{i j}$ and $X_{i t}$. A full set of year dummies is included to control for the macroeconomic situation.

As Heckman (1981) pointed out, the inclusion of lagged dependent variables leads to an initial conditions problem. Because the initial employment state of an individual is influenced by his previous employment history and his observable and unobservable characteristics, not addressing this endogeneity may lead to biased results. Wooldridge (2005) suggested tackling the initial conditions problem in dynamic nonlinear panel data models by explicitly modelling the joint distribution of all endogenous variables conditional on the initial value and the observed history of the strictly exogenous explanatory variables. ${ }^{17}$ His approach follows Mundlak (1978) and Chamberlain (1984) and allows for correlation of the time-invariant, person-specific component $v_{i j}$ with the observed characteristics in the model. We follow Wooldridge (2005) and model

$$
v_{i j}=Y_{i 0} \delta_{j}+\overline{X_{i}} \zeta_{j}+\eta_{i j}
$$

\footnotetext{
${ }^{15}$ See, e.g., Cappellari/Jenkins (2008b), Clark/Kanellopoulos (2013).

${ }^{16}$ We include Locus of Control measured by three dummy variables instead of the continuous variable to allow for a more flexible functional form.

${ }^{17}$ Several studies use the Wooldridge approach, such as the studies by Contoyannis et al. (2004), Stewart (2007), Arulampalam and Stewart (2009), Michaud and Tatsiramos (2011), Clark and Kanellopoulos (2013), Drakos and Konstantinou (2013) and Mosthaf (forthcoming). While Akay (2012) conducts Monte Carlo experiments and finds that the Wooldridge method can be biased in panels shorter than five periods, Rabe-Hesketh and Skrondal (2013) present different possibilities to avoid this bias. Although we use a six-period panel, we follow RabeHesketh and Skrondal (2013) to rule out possible bias.
} 
where $Y_{i 0}$ is the employment state of an individual in the year 2006; $\overline{X_{i}}$ are Mundlak terms consisting of the individual-specific, time-averaged values of the four time-varying explanatory variables age, age squared, number of doctor visits, and marital status; $\eta_{i j}$ are random effects that are orthogonal to the other explanatory variables in the model and are assumed to be normally distributed. Furthermore, to more accurately control for the influence of the previous employment history on the initial employment state than in the standard Wooldridge approach, we follow Mosthaf (fortcoming) and include a vector $H_{i}$ in our model that contains the individual amount of full-time work experience and the individual amount of unemployment experience measured in years. Substituting equation (2) into (1) and including $H_{i}$ in equation (1) yields

$Y_{i j t}^{*}=X_{i t} \beta_{j}+Y_{i t-1} \alpha_{j}+N C_{i} \gamma_{j}+Y_{i 0} \delta_{j}+\bar{X}_{i} \zeta_{j}+H_{i} \psi_{j}+\eta_{i j}+\varepsilon_{i j t}$

To investigate whether state dependence in low pay varies with different scores of Locus of Control, we later include interaction terms between the lagged employment states and the Locus of Control dummy variables $\left(Y_{i t-1} * N C_{i}\right)$. As suggested by Wooldridge (2005), we additionally include interaction terms between the employment state in the first observation period and Locus of Control $\left(Y_{i 0} * N C_{i}\right)$ to consistently control for heterogeneity in state dependence. Including the interaction terms in equation (3) yields

$Y_{i j t}^{*}=X_{i t} \beta_{j}+Y_{i t-1} \alpha_{j}+N C_{i} \gamma_{j}+Y_{i 0} \delta_{j}+\overline{X_{i}} \zeta_{j}+H_{i} \psi_{j}+Y_{i t-1} * N C_{i} \tau_{j}+Y_{i 0} * N C_{i} \kappa_{j}+\eta_{i j}+$ $\varepsilon_{i j t}$.

We assume that $\varepsilon_{i j t}$ has a type I extreme value distribution, which leads to a dynamic multinomial logit model with random effects. Therefore, the probability of an individual $i$ to be in employment state $j$ in time period $t>0$ is

$$
\begin{gathered}
P\left(Y_{i j t} \mid X_{i t}, Y_{i t-1}, N C_{i}, Y_{i 0}, \overline{X_{i}}, H_{i}, Y_{i t-1} * N C_{i}, Y_{i 0} * N C_{i}, \eta_{i j}\right)= \\
\frac{\exp \left(X_{i t} \beta_{j}+Y_{i t-1} \alpha_{j}+N C_{i} \gamma_{j}+Y_{i 0} \delta_{j}+\overline{X_{i}} \zeta_{j}+H_{i} \psi_{j}+Y_{i t-1} * N C_{i} \tau_{j}+Y_{i 0} * N C_{i} \kappa_{j}+\eta_{i j}\right)}{\sum_{k=1}^{3} \exp \left(X_{i t} \beta_{k}+Y_{i t-1} \alpha_{k}+N C_{i} \gamma_{k}+Y_{i 0} \delta_{k}+\overline{X_{i}} \zeta_{k}+H_{i} \psi_{k}+Y_{i t-1} * N C_{i} \tau_{k}+Y_{i 0} * N C_{i} \kappa_{k}+\eta_{i k}\right)}
\end{gathered}
$$

We use higher-wage employment as the reference category in the multinomial logit model. Therefore, for the model to be identified, we set $\beta_{1}, \alpha_{1}, \gamma_{1}, \delta_{1}, \zeta_{1}, \psi_{1}, \tau_{1}, \kappa_{1}$ and $\eta_{i 1}$ to zero. 
We estimate the model by applying adaptive a Gauss-Hermite quadrature with eight quadrature points. $^{18}$

\section{$5 \quad$ Results}

Table 2 shows the results of the different specifications of dynamic multinomial logit models with random effects for the probability of West German men to be higher-paid, low-paid or not working. The employment state "not working" is heterogeneous and is included mainly to control for the possibly endogenous selection of individuals into this employment state. Therefore, results with respect to this employment state should be interpreted with caution.

\subsection{The impact of Locus of Control on the probability to be low-paid or higher-paid}

In model 1, we include the three Locus of Control dummy variables along with the other variables discussed in the previous section except for the interaction terms, the Big Five and reciprocity. ${ }^{19}$ The results for this model are shown in the first two columns of Table 2 . The parameters of the variance-covariance matrix are highly significant, indicating the existence of unobserved heterogeneity even after controlling for Locus of Control. The highly significant coefficients of the lagged employment states "Low pay in t-1" and "Not working in t-1" indicate that there is state dependence in low pay and in the not working employment state. Furthermore, the significant positive coefficients of the employment states in the initial observation period demonstrate the importance of controlling for the initial conditions problem. In addition, the individual amount of unemployment experience prior to 2006 is positively correlated with the probability of being low-paid or not working instead of being higher-paid in period $t$.

The results for the Locus of Control dummy variables show that compared to the reference group of individuals with an external Locus of Control, individuals with a medium Locus of Control or an internal Locus of Control have a significantly lower probability of being lowpaid instead of higher-paid. Individuals with a medium or an internal Locus of Control also have a lower probability of not working instead of being higher-paid. However, the time-

\footnotetext{
${ }^{18}$ Increasing the number of quadrature points in this type of estimation may lead to more precise estimates because the likelihood is evaluated more accurately when the number of quadrature points is higher. To assess the robustness of our results, we reran our models using 12 quadrature points. However, the estimates only differed at the third decimal place.

${ }^{19}$ As a robustness check, we reran all our models using the continuous Locus of Control variable instead of the three dummy variables. However, this change did not alter our findings.
} 
invariant variables in such models might be correlated with the random effects, i.e., they do not necessarily represent causal relationships.

(Table 2 around here)

To examine whether our results are robust towards the inclusion of other non-cognitive skills, we augmented our model by adding the Big Five taxonomy and by including the measures of positive reciprocity and negative reciprocity (see model 2 in Table 2). The coefficients from this augmented model 2 are similar to the coefficients from model 1, which included only Locus of Control. Therefore, the positive impact of Locus of Control on the probability of being higher-paid instead of low-paid or not working is corroborated after controlling for other non-cognitive skills. Interestingly, we find an impact for some of these additional noncognitive skills on the probability of being low-paid instead of higher-paid: the individual scores of Conscientiousness, Agreeableness, and negative reciprocity are positively related to the probability of being low-paid instead of higher-paid.

The coefficients from multinomial logit models cannot be interpreted concerning their economic significance. Therefore, we fix the random effects at their mean value zero, and then calculate the average predicted probabilities to be higher-paid, low-paid or not working from model 2 for the three different Locus of Control categories. ${ }^{20}$ The average predicted probability to be higher-paid is 0.774 for individuals with an external Locus of Control, while for individuals with a medium Locus of Control, this probability is 0.898. Finally, for individuals with an internal Locus of Control, the probability to be higher-paid is 0.937 . The 95\%confidence intervals of these probabilities do not overlap between the different Locus of Control categories, indicating that the probability to be higher-paid is significantly higher for individuals with an internal Locus of Control. ${ }^{21}$

\subsection{The impact of Locus of Control on the probability to escape low pay}

From a dynamic perspective, it is also important to know whether state dependence in low pay varies with individual scores of Locus of Control, i.e., whether individuals with an internal Locus of Control are more likely to exit the low-wage sector by moving to higher-wage employment. To investigate this question, we now interact Locus of Control with the lagged employment state and the employment state in the first observation period. Model 3 in Table 3 gives the results for this interacted version of model 1, i.e., it does not include any non-

\footnotetext{
${ }^{20}$ This approach leads to predictions for typical individuals.

${ }^{21}$ For individuals with an external Locus of Control, the confidence intervals range from 0.762 to 0.786 , while for individuals with a medium Locus of Control this range is 0.890 to 0.907 . For individuals with an internal Locus of Control, the confidence intervals are from 0.930 to 0.943 .
} 
cognitive skills other than Locus of Control. Model 4 gives the results for the interacted version of model 2, i.e., it tests for robustness by additionally including the Big Five measures and reciprocity as well as interactions between these non-cognitive skills and the lagged employment states.

(Table 3 around here)

Except for variables which have been interacted, the coefficients of model 3 are similar to the corresponding coefficients in model 1 in Table 2. As mentioned earlier, "Higher wage in t-1" is the reference category for the dummy variables "Low wage in $\mathrm{t}-1$ " and "Not working in $\mathrm{t}-1$ ". These two variables are the reference categories for their interactions with Locus of Control and therefore describe the individuals in the reference group, i.e., individuals with an external Locus of Control.

The coefficient of "Low wage in t-1" is positive and statistically significant. This finding indicates that for individuals with an external Locus of Control, being low-paid in period $t-1$ increases the probability of being low-paid in period $t$ instead of being higher-paid in period $t$. The coefficients for the interactions between Locus of Control and lagged low pay status are negative but not statistically significant at conventional levels; this indicates that compared to the reference group of individuals with an external Locus of Control who were low-paid in $t-1$, individuals with a medium or an internal Locus of Control have a lower (yet statistically insignificant) risk of being low-paid in period $t$ if they have been low-paid in $t-1$. Therefore, from this model we cannot infer that the probability of escaping low pay is significantly different for individuals with different scores of Locus of Control.

However, the results of model 4 in Table 3 show that the inclusion of the Big Five measures and reciprocity and their interactions with the lagged employment states partly changes our results. First, the coefficient for "Low pay in t-1" has lost its significance and now exhibits a fairly high standard error. This indicates that after controlling for the impact of the Big Five and reciprocity, within the group of individuals with an external Locus of Control the probability of being low-paid in period $t$ does not differ anymore significantly between the individuals who were low-paid in $t-1$ and the individuals who were higher-paid in $t-1$. However, compared to the individuals with an external Locus of Control who were low-paid in $t-1$, individuals with an internal Locus of Control who were low-paid in $t-1$ have a significantly higher probability to be higher-paid in period $t$ (see the interaction term between having an internal Locus of Control and "Low wage in t-1"). This indicates that state 
dependence in low pay is lower for individuals with an internal Locus of Control, i.e., that these individuals have a higher probability of escaping low pay.

We quantify the impact of Locus of Control on the probability of escaping low pay by using the same technique as in the previous subsection 5.1. We use the results of model 4 and fix the random effects at their mean value zero to calculate the average predicted probabilities to be in a specific labour employment state, conditional on the lagged employment state and Locus of Control. The results are presented in Table 4 . We are mainly interested in the probabilities of being higher-paid in period $t$ conditional on being low-paid in period $t-1$ and Locus of Control. These probabilities are presented together with their 95\%-confidence intervals in the first column of Table 4. Conditional on being low-paid in year $t-1$, individuals with an external Locus of Control have a probability of 0.432 to be higher-paid in year $t$. For individuals with a medium Locus of Control, this probability is 0.484 , while for individuals with an internal Locus of Control the probability to be higher-paid in period $t$ is 0.646 . The confidence intervals of the probabilities for individuals with a medium Locus of Control overlap with the confidence intervals for the individuals with an external Locus of Control and with the confidence intervals of the individuals with an internal Locus of Control as well. However, the confidence intervals of the individuals with an external Locus of Control and the confidence intervals of the individuals with an internal Locus of Control do not overlap. This indicates that the probability of low-wage workers to be higher-paid in the next year is clearly higher for individuals with an internal Locus of Control than for individuals with an external Locus of Control. In sum, this evidence indicates that having an internal Locus of Control facilitates escaping low wages.

(Table 4 around here)

\section{Conclusion}

This paper has investigated the impact of non-cognitive skills, in particular Locus of Control, on the wage mobility of male workers at the low-wage margin in West Germany. We apply dynamic multinomial logit models with random effects and investigate whether Locus of Control influences the probability of being higher-paid or low-paid as well as the probability of escaping low wages by moving up to higher-paid employment.

We find a significant amount of state dependence in low pay even after controlling for Locus of Control and other non-cognitive skills, such as the Big Five and reciprocity. Compared to individuals with an external Locus of Control, individuals with a more internal Locus of 
Control have a significantly higher probability of being higher-paid instead of low-paid. Conditional on being low-paid, individuals with an internal Locus of Control additionally have a significantly higher probability of moving to higher-paid employment in the following year than individuals with an external Locus of Control. This indicates that individuals who strongly believe that they control the events in their life have a lower probability of being low-paid. In addition, this also indicates that conditional on being low-paid, individuals who strongly believe that they control the events in their life additionally have a better chance of escaping low wages by moving to higher-wage employment compared to individuals with an external Locus of Control.

Our results suggest that having an internal Locus of Control is an important non-cognitive skill in the context of low wages because this skill may help individuals avoid low-wage jobs and may help individuals to move from low-paid jobs to higher-paid jobs. Labour market policy instruments targeting low-wage workers have to take this finding into account because these heterogeneities can result in different reactions to applied measures. In particular, individuals with a more external LoC may need a higher level of external assistance. In addition, the determination of Locus of Control in childhood or early adulthood may be a starting point for long-term labour market policy measures aimed at improving individual wage mobility. In this context, it would additionally be important to analyse the broader impact of non-cognitive skills on labour market dynamics and to include women, who were not included in this study due their heterogeneous employment trajectories. Furthermore, it would be important to study whether the impact of non-cognitive skills on wage mobility additionally varies with job and firm characteristics. However, these topics are left for future research. 


\section{References}

Akay, Alpaslan (2012): Finite-Sample Comparison of Alternative Methods for Estimating Dynamic Panel Data Models. In: Journal of Applied Econometrics 27(7), p. 1189-1204.

Almlund, Mathilde; Duckworth, Angela L.; Heckman James J.; Kautz, Tim (2011): Personality Psychology and Economics. In: Hanushek, Eric A.; Machin, Stephen; Woessmann, Ludger (eds.) (2011): Handbook of the Economics of Education Volume 4. Amsterdam et al.: Elsevier / North Holland, p. 1-181.

Andersson, Fredrik; Holzer, Harry J.; Lane, Julia I. (2005): Moving Up or Moving On: Who Advances in the Low-Wage Labor Market? New York: Russell Sage Foundation Publications.

Antecol, Heather; Cobb-Clark, Deborah A. (forthcoming): Do Non-Cognitive Skills Help Explain the Occupational Segregation of Young People? In: Labour Economics.

Aretz, Bodo; Gürtzgen, Nicole (2012): What Explains the Decline in Wage Mobility in the German Low-Wage Sector? ZEW Discussion Paper 12-041, Mannheim.

Arulampalam, Wijii; Stewart, Mark B. (2009): Simplified Implementation of the Heckman Estimator of the Dynamic Probit Model and a Comparison with Alternative Estimators. In: Oxford Bulletin of Economics and Statistics 71(5), p. 659-681.

Asplund, Rita; Sloane, Peter J.; Theodossiou, Ioannis (eds.) (1998): Low Pay and Earnings Mobility in Europe. Cheltenham: Edward Elgar Publishing.

Barón, Juan D.; Cobb-Clark, Deborah A. (2010): Are Young People's Educational Outcomes Linked to their Sense of Control? IZA Discussion Paper 4907, Bonn.

Blázquez Cuesta, Maite (2008): Low-Wage Employment and Mobility in Spain. In: LABOUR 22(Special Issue), p. 115-146.

Blázquez Cuesta, Maite; Budría, Santiago (2012): Unemployment Persistence: How Important are Non-cognitive Skills? SOEPpapers on Multidisciplinary Panel Data Research 513, Berlin.

Becker, Anke; Deckers, Thomas; Dohmen, Thomas; Falk, Armin; Kosse, Fabian (2012): The Relationship Between Economic Preferences and Psychological Personality Measures. In: Annual Review of Economics 4(1), p. 453-478.

Caliendo, Marco; Cobb-Clark, Deborah A.; Uhlendorff, Arne (2010): Locus of Control and Job Search Strategies. IZA Discussion Paper 4750, Bonn.

Cappellari, Lorenzo (2002): Do the "Working Poor" Stay Poor? An Analysis of Low Pay Transitions in Italy. In: Oxford Bulletin of Economics and Statistics 64(2), p. 87-110.

Cappellari, Lorenzo (2007): Earnings Mobility Among Italian Low-Paid Workers. In: Journal of Population Economics 20(2), p. 465-482.

Cappellari, Lorenzo; Jenkins, Stephen P. (2008a): Modelling Low Pay Transition Probabilities, Accounting for Panel Attrition, Nonresponse and Initial Conditions. In: Journal of the Royal Statistical Society Series C 57(2), p. 165-186.

Cappellari, Lorenzo; Jenkins, Stephen P. (2008b): Transitions between Unemployment and Low Pay. In: Polachek, Solomon W.; Tatsiramos, Konstantinos (eds.) (2008): Research in Labor Economics Volume 28. Amsterdam: Elsevier, p. 57-79.

Chamberlain, Garry (1984): Panel Data. In: Griliches, Zvi; Intriligator, Michael D. (eds.) (1984): Handbook of Econometrics Volume 2. Amsterdam: North Holland, p. 1247-1318.

Clark, Ken; Kanellopoulos, Nikolaos C. (2013): Low Pay Persistence in Europe. In: Labour Economics 23(C), p. 122-134.

Cobb-Clark, Deborah A.; Schurer, Stefanie (2012): The Stability of Big-Five Personality Traits. In: Economics Letters 115(1), p. 11-15.

Cobb-Clark, Deborah A.; Schurer, Stefanie (2013): Two Economists' Musings on the Stability of Locus of Control. In: The Economic Journal 123(August), p. F358-F400. 
Costa, Paul T.; McCrae, Robert R. (1988): Personality in Adulthood: A Six-Year Longitudinal Study of Self-Reports and Spouse Ratings on the NEO Personality Inventory. In: Journal of Personality and Social Psychology 54(5), p. 853-863.

Contoyannis, Paul; Jones, Andrew M.; Rice, Nigel (2004): The Dynamics of Health in the British Household Panel Survey. In: Journal of Applied Econometrics 19(4), p. 473-503.

Drakos, Konstantinos; Konstantinou, Panagiotis T. (2013): Investment Decisions in Manufacturing: Assessing the Effects of Real Oil Prices and Their Uncertainty. In: Journal of Applied Econometrics 28(1), p. 151-165.

Dyrenforth, Portia S.; Kashy, Deborah A.; Donnellan, Brent M.; Lucas, Richard E. (2010): Predicting Relationship and Life Satisfaction from Personality in Nationally Representative Samples from Three Countries: The Relative Importance of Actor, Partner, and Similarity Effects. Journal of Personality and Social Psychology 99(4), p. 690-702.

European Commission (2004): Labour Market Transitions and Advancement: Temporary Employment and Low-Pay in Europe. In: European Commission (ed.) (2004): Employment in Europe 2004. Luxembourg, p. 159-186.

Groves, Melissa O. (2005): How Important is Your Personality? Labor Market Returns to Personality for Women in the US and UK. In: Journal of Economic Psychology 26(6), p. 827-841.

Heckman, James J. (1981): The Incidental Parameters Problem and the Problem of Initial Conditions in Estimating a Discrete Time-Discrete Data Stochastic Process. In: Manski, Charles F.; McFadden, Daniel (eds.) (1981) Structural Analysis of Discrete Data with Econometric Applications. Cambridge: The MIT Press, p. 179-195.

Heckman, James J.; Pinto, Rodrigo; Savelyev, Peter A. (2012): Understanding the Mechanisms Through Which an Influential Early Childhood Program Boosted Adult Outcomes. NBER Working Papers 18581, Cambridge.

Heckman, James J.; Stixrud, Jora; Urzua, Sergio (2006): The Effects of Cognitive and Noncognitive Abilities on Labor Market Outcomes and Social Behavior. In: Journal of Labor Economics 24(3), p. 411-482.

Heineck, Guido (2011): Does It Pay to Be Nice? Personality and Earnings in the UK. In: Industrial and Labor Relations Review 64(5), p. 1020-1038.

Heineck, Guido; Anger, Silke (2010): The Returns to Cognitive Abilities and Personality Traits in Germany. In: Labour Economics 17(3), p. 535-546.

Knabe, Andreas; Plum, Alexander (2013): Low-Paid Jobs - Springboard to High-Paid Ones? In: LABOUR 27(3), p. 310-330.

McCrae, Robert R.; Costa Jr., Paul T. (1999): A Five-Factor Theory of Personality. In: Pervin, Lawrence A. and John, Oliver P. (eds.) (1999): Handbook of Personality: Theory and Research. New York: Guilford, p. 139-153.

Michaud, Pierre-Carl; Tatsiramos, Konstantinos (2011): Fertility and Female Employment Dynamics in Europe: The Effect of Using Alternative Econometric Modeling Assumptions. In: Journal of Applied Econometrics 26(4), p. 641-668.

Mosthaf, Alexander (forthcoming): Low-Wage Jobs: Stepping Stones or Just Bad Signals? In: the Scottish Journal of Political Economy.

Mosthaf, Alexander; Schank, Thorsten; Schnabel, Claus (2009): Low-Wage Employment Versus Unemployment: Which One Provides Better Prospects for Women? Discussion Paper No. 65, Friedrich-Alexander-University Erlangen-Nuremberg, Nuremberg.

Mosthaf, Alexander; Schnabel, Claus; Stephani, Jens (2011): Low-Wage Careers: Are there Dead-End Firms and Dead-End Jobs? In: Journal for Labour Market Research 43(3), p. 231-249.

Müller, Gerrit; Plug, Erik (2006): Estimating the Effect of Personality on Male and Female Earnings. In: Industrial and Labor Relations Review 60(1), p. 3-22.

Mundlak, Yair (1978): On the Pooling of Time Series and Cross Section Data. In: Econometrica 46(1), p. 69-85. 
Lucas, Richard E.; Donnellan, Brent M. (2011): Personality Development Across the Life Span: Longitudinal Analyses With a National Sample From Germany. Journal of Personality and Social Psychology 101(4), p. 847-861.

Peter, Frauke H. (2013): Trick or Treat? Maternal Involuntary Job Loss and Children's NonCognitive Skills. DIW Discussion Paper 1297, Berlin.

Rabe-Hesketh, Sophia; Skrondal, Anders (2013): Avoiding Biased Versions of Wooldridge's Simple Solution to the Initial Conditions Problem. In: Economic Letters 120(2), p. 346-349.

Richter, David; Metzing, Maria; Weinhardt, Michael; Schupp, Jürgen (2013): SOEP Scales Manual. SOEP Survey Papers 138: Series C, Berlin.

Riphahn, Regina T.; Schnitzlein, Daniel D. (2011): Wage Mobility in East and West Germany. IZA Discussion Papers 6246, Bonn.

Roberts, Brent W.; Walton, Kate E.; Viechtbauer, Wolfgang (2006): Patterns of Mean-Level Change in Personality Traits Across the Life Course: A Meta-Analysis of Longitudinal Studies. In: Psychological Bulletin 132 (1), p. 1-25.

Roberts, Brent W.; DelVecchio, Wendy F. (2000): The Rank-Order Consistency of Personality Traits from Childhood to Old Age: A Quantitative Review of Longitudinal Studies. In: Psychological Bulletin 126(1), p. 3-25.

Rotter, Julian B. (1966): Generalized Expectancies for Internal Versus External Control of Reinforcement. In: Psychological Monographs: General and Applied 80(1), p. 1-28.

Schank, Thorsten; Schnabel, Claus; Stephani, Jens (2009): Geringverdiener: Wem und wie gelingt der Aufstieg? In: Journal of Economics and Statistics 229(5), p. 584-614.

Specht, Jule; Egloff, Boris; Schmukle, Stefan C. (2013): Everything Under Control? The Effects of Age, Gender, and Education on Trajectories of Perceived Control in a Nationally Representative German Sample. In: Developmental Psychology 49(2), p. 353-364.

Specht, Jule; Egloff, Boris; Schmukle, Stefan C. (2011): Stability and Change of Personality Across the Life Course: The Impact of Age and Major Life Events on Mean-Level and Rank-Order Stability of the Big Five. In: Journal of Personality and Social Psychology 101(4), p. 862-882.

Stephani, Jens (2012): Wage Growth and Career Patterns of German Low-Wage Workers. IAB-Discussion Paper 1/2012, Nuremberg.

Stephani, Jens (2013): Does It Matter Where You Work? Employer Characteristics and the Wage Growth of Low-Wage Workers and Higher-Wage Workers. IAB Discussion Paper 4/2013, Nuremberg.

Stephens, Mark W.; Delys, Pamela (1973): External Control Expectancies Among Disadvantaged Children at Preschool Age. In: Child Development 44 (3), p. 670-674.

Stewart, Mark B. (2007): The Interrelated Dynamics of Unemployment and Low-Wage Employment. In: Journal of Applied Econometrics 22(3), p. 511-531.

Stewart, Mark B.; Swaffield, Joanna K. (1999): Low Pay Dynamics and Transition Probabilities. In: Economica 66(1), p. 23-42.

Uhlendorff, Arne (2006): From No Pay to Low Pay and Back Again? A Multi-State Model of Low Pay Dynamics. IZA Discussion Paper No.2482, Bonn.

Wagner, Gert G.; Frick, Joachim R.; Schupp, Jürgen (2007): The German Socio-Economic Panel Study (SOEP) - Scope, Evolution and Enhancements. In: Schmollers Jahrbuch 127(1), p. 139-169.

Wang, Li-Ya.; Kick, Edward; Fraser, James; Burns, Thomas J. (1999): Status Attainment in America: The Roles of Locus of Control and Self-Esteem in Educational and Occupational Outcomes. In: Sociological Spectrum 19, p. 281-298.

Wooldridge, Jeffrey M. (2005): Simple Solutions to the Initial Conditions Problem in Dynamic, Nonlinear Panel Data Models with Unobserved Heterogeneity. In: Journal of Applied Econometrics 20(1), p. 39-54. 


\section{Figures and Tables}

Table 1: Descriptive statistics of the sample

Higher wage Low wage Non working

$\mathrm{N}=10,456$

$86.27 \%$

$4.61 \%$

$9.12 \%$

\section{Non-cognitive skills}

Locus of Control

Measured as continuous variable

(scale from 1 to 7 )

$\begin{array}{lll}4.88 & 4.50 & 4.27\end{array}$

Measured by three dummy variables

$\begin{array}{rlll}\text { external (yes=1) } & 0.18 & 0.34 & 0.42 \\ \text { medium (yes=1) } & 0.37 & 0.33 & 0.33 \\ \text { internal (yes=1) } & 0.45 & 0.33 & 0.24\end{array}$

Big Five personality traits (scale from 1 to 7 )

$$
\text { Openness }
$$

4.42

4.38

4.37

Conscientiousness

Extraversion

4.72

4.65

4.61

Agreeableness

5.27

5.44

5.17

Reciprocity (scale from 1 to 7)

Neuroticism

3.60

3.84

4.10

\section{Positive}

5.88

6.03

5.86

Negative

3.26

3.64

3.57

\section{Individual characteristics}

No German citizen (yes=1)

Age

$\begin{array}{lll}0.12 & 0.21 & 0.25 \\ 45.14 & 41.18 & 48.68 \\ 7.24 & 7.29 & 16.66 \\ 0.75 & 0.55 & 0.63\end{array}$

Married (1=yes)

0.75

0.63

Education

General elementary education ( $1=$ yes)

0.09

$0.15 \quad 0.20$

Middle vocational educ./Abitur (1=yes)

Higher vocational educ. and higher educ.

0.52

$0.70 \quad 0.60$

(1=yes)

Fulltime work experience until 2006 (in years)

0.39

0.15

0.20

Unemployment experience until 2006 (in years)

20.89

15.34

18.91

0.34

1.71

3.66

Note: own calculations based on SOEPv28, pooled (2007-2011). 
Figure 1: Employment state by Locus of Control

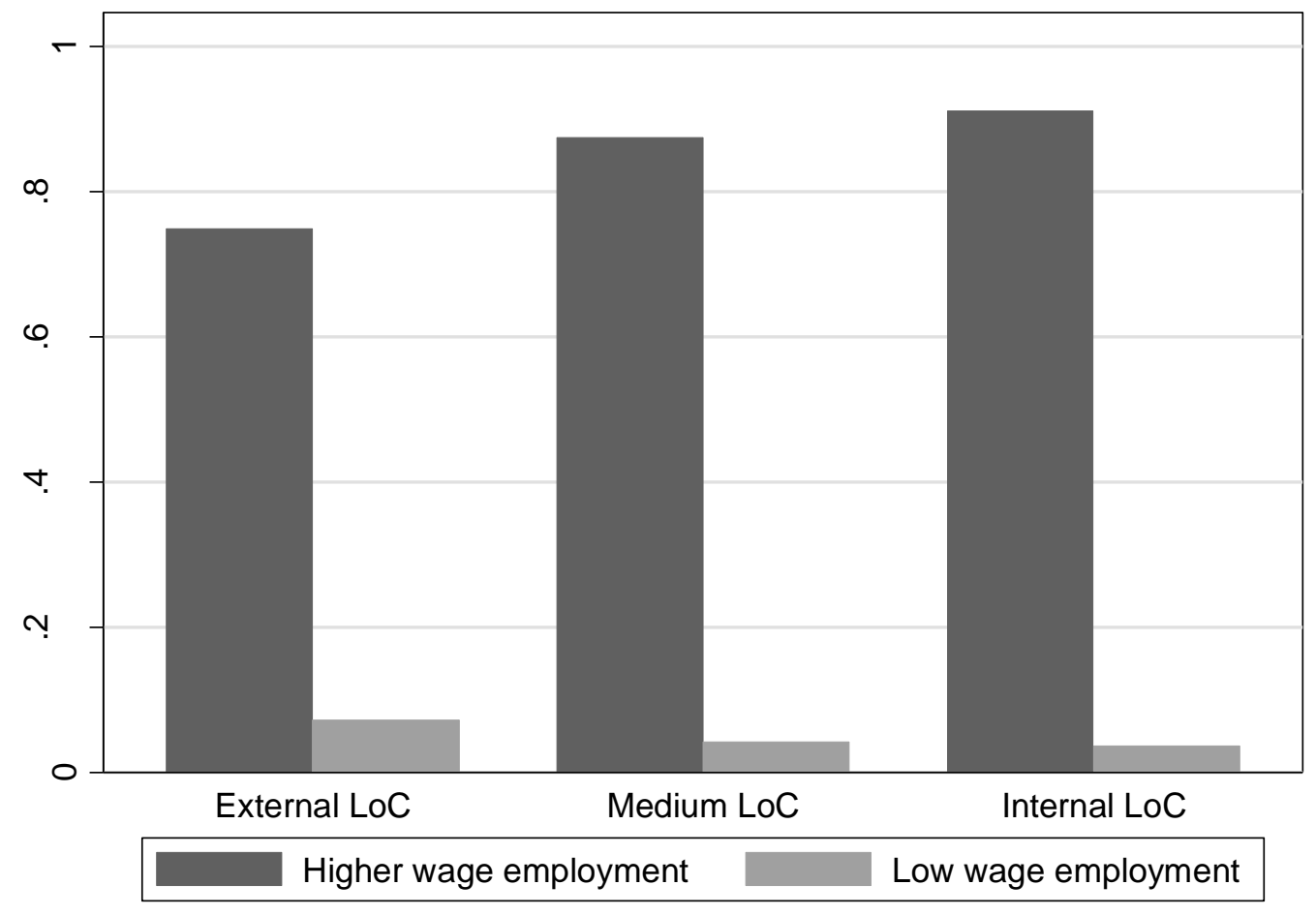

Note: own calculations based on SOEPv28, pooled (2007-2011). 
Figure 2: Wage mobility of low-wage workers by Locus of Control

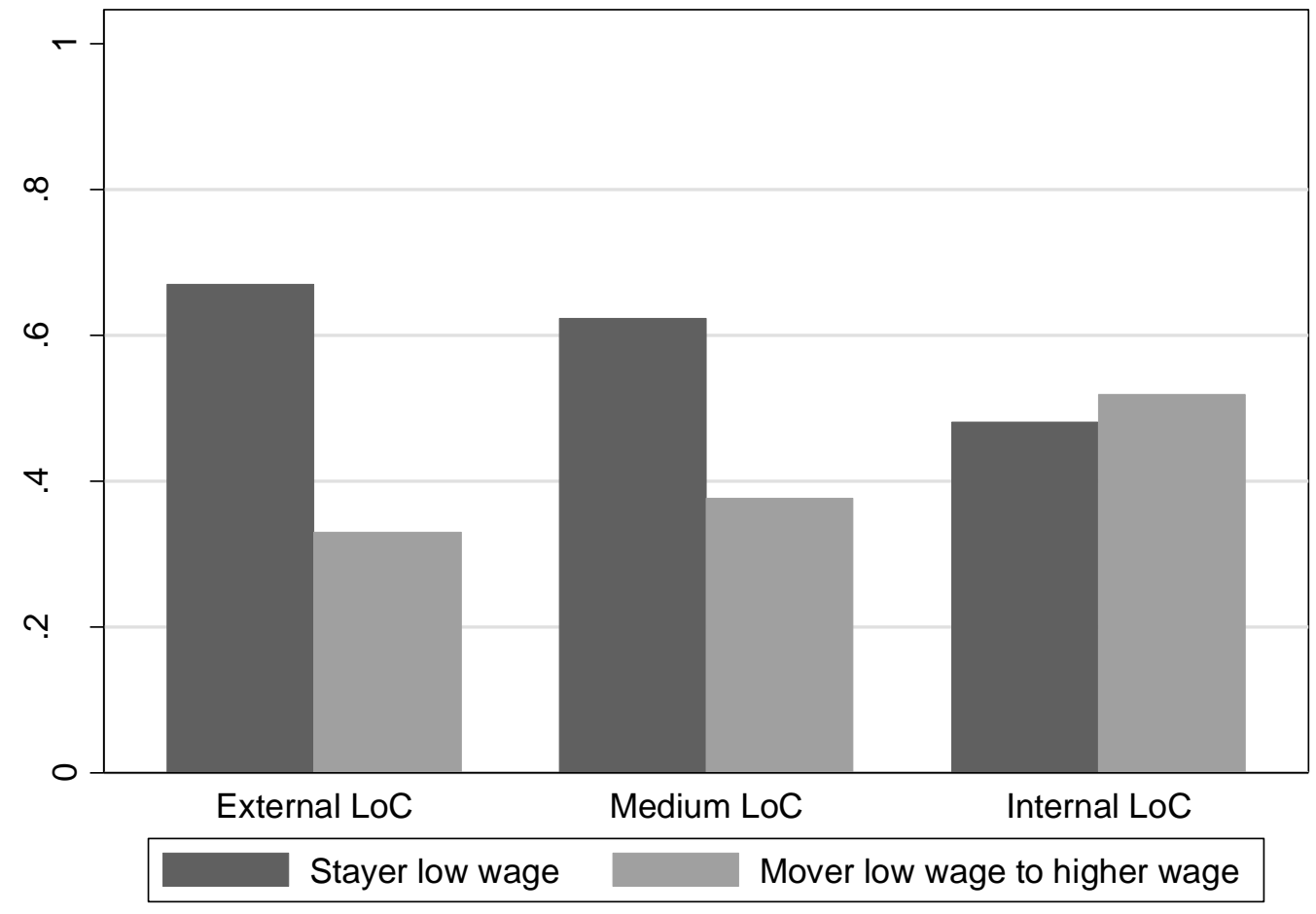

Note: own calculations based on SOEPv28, pooled (2007-2011). 
Table 2: Models 1-2, dynamic multinomial logit models with random effects, no interactions

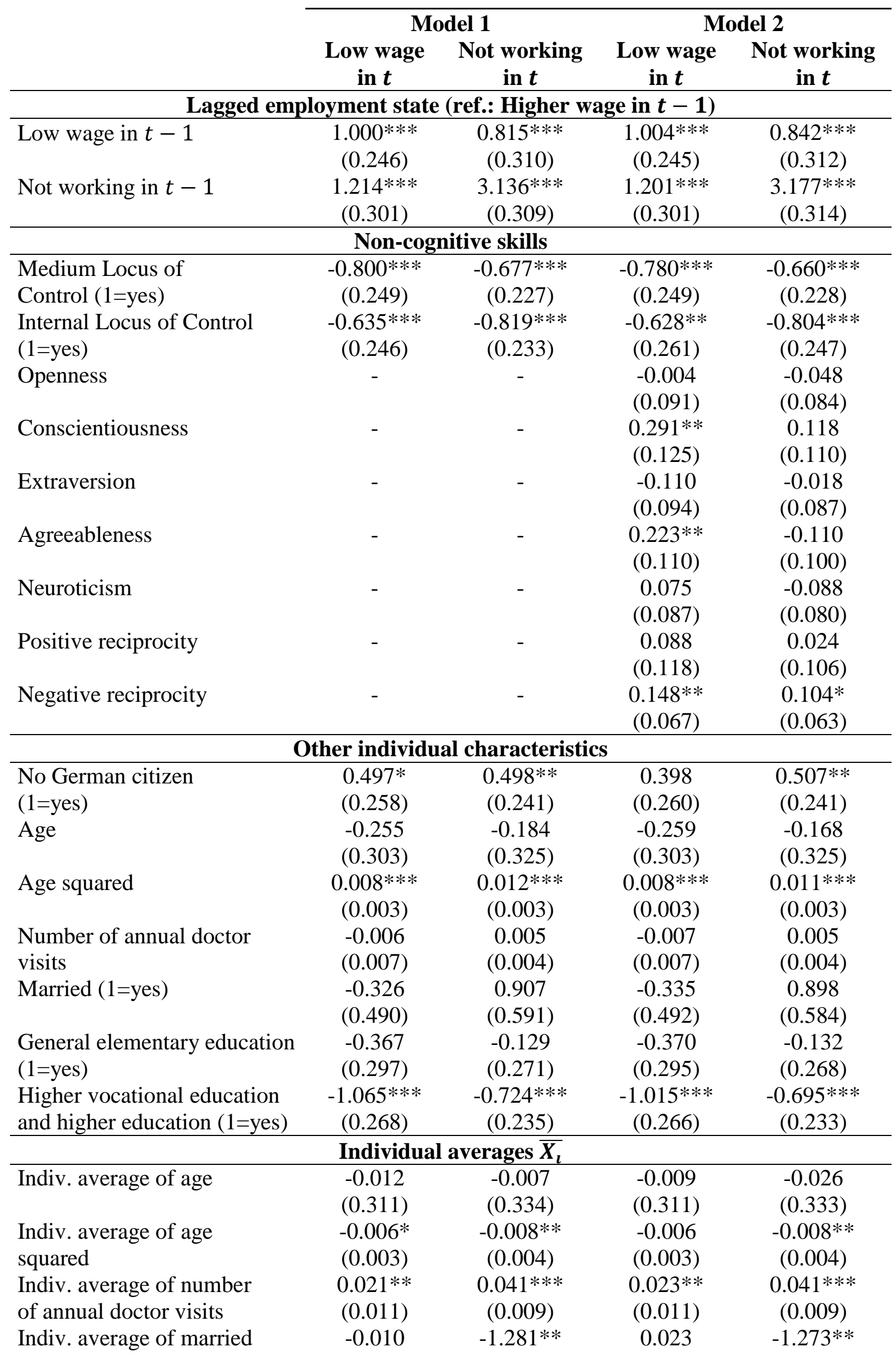




$$
(0.544) \quad(0.628) \quad(0.545)
$$

Initial employment state (ref.: Higher wage in $\boldsymbol{t}=\mathbf{0}$ )

\begin{tabular}{lcccc}
\hline Low wage in $t=0$ & $4.605^{* * *}$ & $2.706^{* * *}$ & $4.514 * * *$ & $2.640^{* * *}$ \\
Not working in $t=0$ & $(0.451)$ & $(0.477)$ & $(0.444)$ & $(0.474)$ \\
& $4.147^{* * *}$ & $4.164 * * *$ & $4.114 * * *$ & $4.109 * * *$ \\
Fulltime work experience & $(0.519)$ & $(0.624)$ & $(0.516)$ & $(0.633)$ \\
until 2006, in years & 0.002 & $-0.079 * * *$ & -0.010 & $-0.083^{* * *}$ \\
Unemployment experience & $(0.027)$ & $(0.022)$ & $(0.027)$ & $(0.022)$ \\
until 2006, in years & $0.205^{* * *}$ & $0.258^{* * *}$ & $0.195 * * *$ & $0.250^{* * *}$ \\
\hline Constant & $(0.062)$ & $(0.055)$ & $(0.061)$ & $(0.054)$ \\
\hline & 1.669 & -1.975 & -1.919 & -1.873 \\
Variance $\eta_{2}$ & $(2.424)$ & $(2.344)$ & $(2.673)$ & $(2.532)$ \\
Variance $\eta_{3}$ & $5.107(0.891)^{* * *}$ & $4.885(0.861)^{* * *}$ \\
Covariance $\eta_{2}, \eta_{3}$ & $4.082(1.017)^{* * *}$ & $3.844(1.003)^{* * *}$ \\
AIC & $3.937(0.793)^{* * *}$ & $3.768(0.773)^{* * *}$ \\
Log Likelihood & 4675.422 & 4672.823 \\
Observations & -2286.7112 & -2271.4117 \\
\hline
\end{tabular}

Notes: own calculations based on SOEP v28, pooled (2007-2011). Standard errors in parentheses. Significance levels: $* * * p<0.01, * * \mathrm{p}<0.05$, $* \mathrm{p}<0.1$. Reference groups: external Locus of Control, middle vocational education/Abitur. Full set of year dummies included. 
Table 3: Models 3-4, dynamic multinomial logit models with random effects, with interactions

\begin{tabular}{|c|c|c|c|c|}
\hline & \multirow{2}{*}{\multicolumn{2}{|c|}{ Model 3}} & & \\
\hline & & & \multicolumn{2}{|c|}{ Model 4} \\
\hline & $\begin{array}{c}\text { Low wage } \\
\text { in } t\end{array}$ & $\begin{array}{l}\text { Not working } \\
\text { in } t\end{array}$ & $\begin{array}{c}\text { Low wage } \\
\text { in } t\end{array}$ & $\begin{array}{c}\text { Not working } \\
\text { in } t\end{array}$ \\
\hline \multicolumn{5}{|c|}{ Lagged employment state (ref.: Higher wage in $t-1)$} \\
\hline \multirow[t]{2}{*}{ Low wage in $t-1$} & $1.397 * * *$ & $0.863 *$ & -0.137 & -1.630 \\
\hline & $(0.392)$ & $(0.456)$ & $(2.434)$ & $(2.925)$ \\
\hline \multirow[t]{2}{*}{ Not working in $t-1$} & $1.047 * *$ & $2.911 * * *$ & -4.399 & 1.193 \\
\hline & $(0.487)$ & $(0.438)$ & $(3.583)$ & $(3.006)$ \\
\hline \multicolumn{5}{|c|}{ Non-cognitive skills } \\
\hline Medium Locus of & $-0.896 * * *$ & $-0.893 * * *$ & $-0.808 * *$ & $-0.928 * * *$ \\
\hline Control (1=yes) & $(0.322)$ & $(0.291)$ & $(0.321)$ & $(0.294)$ \\
\hline Internal Locus of Control & $-0.638 * *$ & $-0.896 * * *$ & -0.492 & $-1.047 * * *$ \\
\hline (1=yes) & $(0.305)$ & $(0.285)$ & $(0.324)$ & $(0.311)$ \\
\hline \multirow[t]{2}{*}{ Openness } & - & - & -0.111 & 0.036 \\
\hline & & & $(0.113)$ & $(0.107)$ \\
\hline \multirow[t]{2}{*}{ Conscientiousness } & - & - & $0.394 * *$ & 0.227 \\
\hline & & & $(0.169)$ & $(0.147)$ \\
\hline \multirow[t]{2}{*}{ Extraversion } & - & - & -0.151 & 0.035 \\
\hline & & & $(0.121)$ & $(0.114)$ \\
\hline \multirow[t]{2}{*}{ Agreeableness } & - & - & $0.288 * *$ & $-0.293 * *$ \\
\hline & & & $(0.142)$ & $(0.130)$ \\
\hline \multirow[t]{2}{*}{ Neuroticism } & - & - & $0.200 *$ & -0.138 \\
\hline & & & $(0.109)$ & $(0.102)$ \\
\hline \multirow[t]{2}{*}{ Positive reciprocity } & - & - & 0.066 & 0.039 \\
\hline & & & $(0.155)$ & $(0.137)$ \\
\hline \multirow[t]{2}{*}{ Negative reciprocity } & - & - & $0.213 * *$ & 0.005 \\
\hline & & & $(0.085)$ & $(0.083)$ \\
\hline
\end{tabular}

\section{Interactions between non-cognitive skills and Low wage in $t-1$}

Medium Locus of

Control * Low wage in $t-1$

Internal Locus of Control

* Low wage in $t-1$

Openness * Low wage

in $t-1$

Conscientiousness * Low

wage in $t-1$

Extraversion * Low wage

in $t-1$

Agreeableness * Low wage

in $t-1$

Neuroticism * Low wage

in $t-1$

Positive reciprocity * Low

wage in $t-1$

Negative reciprocity $*$

Low wage in $t-1$

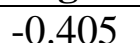

$(0.520)$

$-0.728$

$(0.494)$

-
0.121

(0.620)

$-0.177$

(0.627)
$-0.555$

(0.541)

$-1.364 * *$

(0.573)

$0.418 * *$

(0.202)

$-0.119$

(0.281)

0.276

(0.189)

0.028

(0.241)

$-0.256$

(0.191)

0.113

(0.270)

$-0.097$

(0.132)
0.076

(0.642)

$-0.532$

(0.702)

0.360

(0.250)

$-0.167$

(0.347)

0.267

(0.250)

0.386

(0.310)

$-0.239$

(0.231)

$-0.133$

(0.324)

0.160

(0.167)

\section{Interactions between non-cognitive skills and Not working in $t-1$}

Medium Locus of

0.237

$-0.099$

0.917

Control * Not working in $t-1$

(0.680)

$(0.565)$

$(0.720)$

(0.603)

Internal Locus of Control

0.367

$-0.110$

$-0.200$

0.121 


\begin{tabular}{|c|c|c|c|c|}
\hline$*$ Not working in $t-1$ & $(0.681)$ & $(0.563)$ & $(0.766)$ & $(0.643)$ \\
\hline $\begin{array}{l}\text { Openness * Not working } \\
\text { in } t-1\end{array}$ & - & - & $\begin{array}{c}0.091 \\
(0.246)\end{array}$ & $\begin{array}{l}-0.171 \\
(0.205)\end{array}$ \\
\hline Conscientiousness $*$ & - & - & -0.143 & $-0.746^{* *}$ \\
\hline Not working in $t-1$ & & & $(0.373)$ & $(0.322)$ \\
\hline $\begin{array}{l}\text { Extraversion } * \text { Not working } \\
\text { in } t-1\end{array}$ & - & - & $\begin{array}{l}0.728 * * * \\
(0.280)\end{array}$ & $\begin{array}{c}0.557 * * \\
(0.238)\end{array}$ \\
\hline $\begin{array}{l}\text { Agreeableness } * \text { Not working } \\
\text { in } t-1\end{array}$ & - & - & $\begin{array}{c}0.245 \\
(0.332)\end{array}$ & $\begin{array}{c}0.368 \\
(0.265)\end{array}$ \\
\hline $\begin{array}{l}\text { Neuroticism * Not working } \\
\text { in } t-1\end{array}$ & - & - & $\begin{array}{l}-0.209 \\
(0.245)\end{array}$ & $\begin{array}{c}0.212 \\
(0.202)\end{array}$ \\
\hline Positive reciprocity $*$ & - & - & 0.271 & 0.044 \\
\hline Not working in $t-1$ & & & $(0.334)$ & $(0.277)$ \\
\hline Negative reciprocity $*$ & - & - & 0.204 & $0.401 * *$ \\
\hline Not working in $t-1$ & & & $(0.198)$ & $(0.177)$ \\
\hline \multicolumn{5}{|c|}{ Other individual characteristics } \\
\hline No German citizen & $0.491 *$ & $0.509 * *$ & 0.344 & $0.511 * *$ \\
\hline (1=yes) & $(0.259)$ & $(0.240)$ & $(0.259)$ & $(0.243)$ \\
\hline \multirow[t]{2}{*}{ Age } & -0.234 & -0.176 & -0.208 & -0.091 \\
\hline & $(0.305)$ & $(0.327)$ & $(0.307)$ & $(0.331)$ \\
\hline \multirow[t]{2}{*}{ Age squared } & $0.008 * * *$ & $0.011 * * *$ & $0.008 * *$ & $0.011 * * *$ \\
\hline & $(0.003)$ & $(0.003)$ & $(0.003)$ & $(0.003)$ \\
\hline Number of annual doctor & -0.006 & 0.005 & -0.006 & 0.006 \\
\hline visits & $(0.007)$ & $(0.004)$ & $(0.007)$ & $(0.004)$ \\
\hline \multirow[t]{2}{*}{ Married (1=yes) } & -0.387 & 0.924 & -0.383 & 0.882 \\
\hline & $(0.494)$ & $(0.593)$ & $(0.505)$ & $(0.594)$ \\
\hline General elementary education & -0.360 & -0.120 & -0.428 & -0.161 \\
\hline (1=yes) & $(0.297)$ & $(0.270)$ & $(0.295)$ & $(0.273)$ \\
\hline Higher vocational education & $-1.089 * * *$ & $-0.725 * * *$ & $-1.044 * * *$ & $-0.675 * * *$ \\
\hline and higher education ( $1=y e s)$ & $(0.269)$ & $(0.235)$ & $(0.267)$ & $(0.234)$ \\
\hline
\end{tabular}

\begin{tabular}{|c|c|c|c|c|}
\hline \multicolumn{5}{|c|}{ Individual averages $\overline{X_{L}}$} \\
\hline Indiv. average of age & $\begin{array}{l}-0.033 \\
(0.314)\end{array}$ & $\begin{array}{c}0.003 \\
(0.336)\end{array}$ & $\begin{array}{l}-0.045 \\
(0.316)\end{array}$ & $\begin{array}{l}-0.102 \\
(0.340)\end{array}$ \\
\hline Indiv. average of age & -0.005 & $-0.008 * *$ & -0.005 & $-0.007 *$ \\
\hline squared & $(0.003)$ & $(0.004)$ & $(0.003)$ & $(0.004)$ \\
\hline Indiv. average of number & $0.021^{*}$ & $0.042 * * *$ & $0.019^{*}$ & $0.041 * * *$ \\
\hline of annual doctor visits & $(0.011)$ & $(0.009)$ & $(0.011)$ & $(0.009)$ \\
\hline Indiv. average of married & $\begin{array}{c}0.043 \\
(0.548)\end{array}$ & $\begin{array}{c}-1.293 * * \\
(0.629)\end{array}$ & $\begin{array}{c}0.030 \\
(0.556)\end{array}$ & $\begin{array}{c}-1.265^{* *} \\
(0.630)\end{array}$ \\
\hline \multicolumn{5}{|c|}{ Initial employment state (ref.: Higher wage in $t=0$ ) } \\
\hline Low wage in $t=0$ & $\begin{array}{l}3.834 * * * \\
(0.653)\end{array}$ & $\begin{array}{c}2.254 * * * \\
(0.654)\end{array}$ & $\begin{array}{c}5.724 \\
(3.680)\end{array}$ & $\begin{array}{c}1.872 \\
(3.867)\end{array}$ \\
\hline Not working in $t=0$ & $\begin{array}{c}4.128 * * * \\
(0.697)\end{array}$ & $\begin{array}{c}4.082 * * * \\
(0.730)\end{array}$ & $\begin{array}{c}13.893 * * * \\
(4.008)\end{array}$ & $\begin{array}{l}7.537 * * \\
(3.588)\end{array}$ \\
\hline $\begin{array}{l}\text { Fulltime work experience } \\
\text { until } 2006 \text {, in years }\end{array}$ & $\begin{array}{c}-4.6 \mathrm{e}-04 \\
(0.027)\end{array}$ & $\begin{array}{c}-0.081 * * * \\
(0.022)\end{array}$ & $\begin{array}{l}-0.016 \\
(0.028)\end{array}$ & $\begin{array}{c}-0.088 * * * \\
(0.023)\end{array}$ \\
\hline $\begin{array}{l}\text { Unemployment experience } \\
\text { until 2006, in years }\end{array}$ & $\begin{array}{l}0.211 * * * \\
(0.062)\end{array}$ & $\begin{array}{c}0.262 * * * \\
(0.056)\end{array}$ & $\begin{array}{l}0.218 * * * \\
(0.063)\end{array}$ & $\begin{array}{l}0.265^{* * * *} \\
(0.057)\end{array}$ \\
\hline
\end{tabular}

Interactions between non-cognitive skills and Low wage in $\boldsymbol{t}=\mathbf{0}$

\begin{tabular}{lcccc}
\hline Medium Locus of & 1.114 & 0.817 & 1.091 & 0.775 \\
Control * Low wage in $t=0$ & $(0.773)$ & $(0.815)$ & $(0.782)$ & $(0.829)$ \\
Internal Locus of Control & 0.986 & 0.190 & 1.381 & 0.483
\end{tabular}


$*$ Low wage in $t=0$

Openness * Low wage in $t=0$

Conscientiousness * Low

wage in $t=0$

Extraversion * Low wage

in $t=0$

Agreeableness * Low wage

in $t=0$

Neuroticism * Low wage

in $t=0$

Positive reciprocity * Low

wage in $t=0$

Negative reciprocity $*$

Low wage in $t=0$

$$
\text { (0.763) }
$$

(0.853)

(0.846)

(0.948)

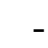

$-$

$-0.079$

$-0.264$

(0.289)

(0.318)

0.071

0.303

$(0.402)$

(0.444)

$-0.605 * *$

$-0.520$

(0.285)

(0.329)

0.294

0.187

(0.343)

(0.383)

0.026

0.156

(0.310)

(0.340)

$-0.308$

0.030

(0.394)

(0.428)

0.183

0.067

(0.199)

(0.217)

\begin{tabular}{|c|c|c|c|c|}
\hline & & & & \\
\hline Medium Locus of & 0.123 & -0.316 & 0.086 & -0.444 \\
\hline Control $*$ Not working in $t=0$ & $(0.790)$ & $(0.685)$ & $(0.823)$ & $(0.729)$ \\
\hline Internal Locus of Control & -0.359 & 0.451 & -0.396 & 0.388 \\
\hline$*$ Not working in $t=0$ & $(0.836)$ & $(0.716)$ & $(0.903)$ & $(0.793)$ \\
\hline Openness * Not working & - & - & 0.029 & -0.122 \\
\hline in $t=0$ & & & $(0.302)$ & $(0.263)$ \\
\hline Conscientiousness $*$ & - & - & -0.386 & 0.265 \\
\hline Not working in $t=0$ & & & $(0.410)$ & $(0.367)$ \\
\hline $\begin{array}{l}\text { Extraversion } * \text { Not working } \\
\text { in } t=0\end{array}$ & - & - & $\begin{array}{l}-0.123 \\
(0.309)\end{array}$ & $\begin{array}{l}-0.399 \\
(0.276)\end{array}$ \\
\hline $\begin{array}{l}\text { Agreeableness } * \text { Not working } \\
\text { in } t=0\end{array}$ & - & - & $\begin{array}{l}-0.703^{*} \\
(0.377)\end{array}$ & $\begin{array}{l}-0.215 \\
(0.321)\end{array}$ \\
\hline $\begin{array}{l}\text { Neuroticism } * \text { Not working } \\
\text { in } t=0\end{array}$ & - & - & $\begin{array}{l}-0.146 \\
(0.270)\end{array}$ & $\begin{array}{l}-0.121 \\
(0.239)\end{array}$ \\
\hline Positive reciprocity $*$ & - & - & -0.172 & 0.017 \\
\hline Not working in $t=0$ & & & $(0.376)$ & $(0.333)$ \\
\hline Negative reciprocity $*$ & - & - & $-0.545 * *$ & $-0.373 *$ \\
\hline Not working in $t=0$ & & & $(0.238)$ & $(0.212)$ \\
\hline Constant & $\begin{array}{l}1.675 \\
(2.434)\end{array}$ & $\begin{array}{l}-2.278 \\
(2.353)\end{array}$ & $\begin{array}{l}-3.028 \\
(2.804)\end{array}$ & $\begin{array}{l}-1.567 \\
(2.676)\end{array}$ \\
\hline Variance $\eta_{2}$ & 5.096 & $89) * * *$ & 4.630 & $25)^{* * *}$ \\
\hline Variance $\eta_{3}$ & 4.011 & $30) * * *$ & 3.783 & $48) * * *$ \\
\hline Covariance $\eta_{2}, \eta_{3}$ & 3.900 & 97)*** & 3.781 & 30) $* * *$ \\
\hline AIC & & 94 & & \\
\hline Log Likelihood & & 468 & -22 & 537 \\
\hline Observations & & & & \\
\hline
\end{tabular}


Table 4: Predicted probabilities to be in a given employment state in $t$, conditional on Locus of Control and employment state in $t-1$, from model 4

\begin{tabular}{|c|c|c|c|c|c|c|c|c|c|}
\hline \multirow{5}{*}{$\begin{array}{l}\text { Higher wage in } t-1 \\
\text { Low wage in } t-1 \\
\text { Not working in } t-1\end{array}$} & \multicolumn{9}{|c|}{ External Locus of Control } \\
\hline & \multicolumn{3}{|c|}{ Higher wage in $t$} & \multicolumn{3}{|c|}{ Low wage in $t$} & \multicolumn{3}{|c|}{ Not working in $t$} \\
\hline & 0.962 & 0.953 & 0.972 & 0.016 & 0.010 & 0.023 & 0.021 & 0.014 & 0.028 \\
\hline & 0.432 & 0.333 & 0.532 & 0.413 & 0.303 & 0.523 & 0.154 & 0.096 & 0.213 \\
\hline & 0.107 & 0.078 & 0.137 & 0.068 & 0.040 & 0.096 & 0.825 & 0.786 & 0.864 \\
\hline & \multicolumn{9}{|c|}{ Medium Locus of Control } \\
\hline & \multicolumn{3}{|c|}{ Higher wage in $t$} & \multicolumn{3}{|c|}{ Low wage in $t$} & \multicolumn{3}{|c|}{ Not working in $t$} \\
\hline Higher wage in $t-1$ & 0.981 & 0.976 & 0.986 & 0.010 & 0.006 & 0.014 & 0.009 & 0.006 & 0.012 \\
\hline Low wage in $t-1$ & 0.484 & 0.378 & 0.591 & 0.419 & 0.314 & 0.523 & 0.097 & 0.052 & 0.143 \\
\hline \multirow[t]{3}{*}{ Not working in $t-1$} & 0.171 & 0.124 & 0.219 & 0.059 & 0.031 & 0.087 & 0.770 & 0.718 & 0.822 \\
\hline & \multicolumn{9}{|c|}{ Internal Locus of Control } \\
\hline & \multicolumn{3}{|c|}{ Higher wage in $t$} & \multicolumn{3}{|c|}{ Low wage in $t$} & \multicolumn{3}{|c|}{ Not working in $t$} \\
\hline Higher wage in $t-1$ & 0.986 & 0.982 & 0.990 & 0.008 & 0.005 & 0.011 & 0.006 & 0.003 & 0.009 \\
\hline Low wage in $t-1$ & 0.646 & 0.543 & 0.748 & 0.298 & 0.199 & 0.396 & 0.056 & 0.026 & 0.087 \\
\hline Not working in $t-1$ & 0.238 & 0.183 & 0.292 & 0.065 & 0.032 & 0.099 & 0.697 & 0.637 & 0.757 \\
\hline
\end{tabular}

Notes: own calculations based on SOEP v28, pooled (2007-2011). Predicted transition probabilities calculated from model 4, fixing the random effects at their mean value zero. $95 \%$-confidence intervals in parentheses. 


\section{Appendix}

Table A1: Measurement of Locus of Control in the SOEP questionnaire

\section{Locus of Control}

How my life goes depends on me.

Internal $\mathrm{LoC}$

If a person is socially or politically active, he/she can have an effect on social conditions.

Internal LoC

One has to work hard in order to succeed.

Internal LoC

Compared to other people, I have not achieved what I deserved.

External LoC

I frequently have the experience that other people have a controlling influence over my life.

External LoC

The opportunities that I have in life are determined by the social conditions.

External LoC

I have little control over the things that happen in my life.

External LoC

Source: SOEP questionnaire, SOEPv28. 
Table A2: $\quad$ Measurement of the Big Five inventory in the SOEP questionnaire

\section{I see myself as someone who ...}

is original, comes up with new ideas

values artistic experiences

has an active imagination

does a thorough job

does things effectively and efficiently

tend to be lazy (reversed)

is communicative, talkative

is outgoing, sociable

is reserved (reversed)

is sometimes somewhat rude to others (reversed)

has a forgiving nature

is considerate and kind to others

worries a lot

gets nervous easily

is relaxed, handles stress well (reversed)
Openness to experience

Openness to experience

Openness to experience

Conscientiousness

Conscientiousness

Conscientiousness

Extraversion

Extraversion

Extraversion

Agreeableness

Agreeableness

Agreeableness

Neuroticism

Neuroticism

Neuroticism

Source: SOEP questionnaire, SOEPv28. 
Table A3: Measurement of reciprocity in the SOEP questionnaire

\section{Reciprocity}

If someone does me a favor, I am prepared to return it.

I go out of my way to help somebody who has been kind to me before.

I am ready to undergo personal costs to help somebody who helped me before.

If I suffer a serious wrong, I will take revenge as soon as possible, no matter what the cost.

If somebody puts me in a difficult position, I will do the same to him/her..

If somebody offends me, I will offend him/her back.
Positive reciprocity

Positive reciprocity

Positive reciprocity

Negative reciprocity

Negative reciprocity

Negative reciprocity

Source: SOEP questionnaire, SOEPv28. 